\title{
Imaging and Sounding of Ice Fields With Airborne Coherent Radars
}

\author{
Charles Elachi and Walter E. Brown, Jr. \\ Jet Propulsion Laboratory Space Sciences Diviston, Calıfornia Institute of Technology, Pasadena, Califorma 91103
}

\begin{abstract}
Airborne coherent radar observations of i e fields conducted in the last 4 years are presented and discussed These ob er a jons $\mathrm{c}$ ntain radar $\tau$ agery of glaciers in southeast Alask a imagery of jastal and ed ce $n$ northern Alaska and the Beau ort Sea. a d sou ding $t$ layered onturerta $e$ in Green and
\end{abstract}

\section{INTRODUCTION}

The recent development of the synthetic aperture imaging radar [Brown and Porcello 1969 Harger 1970 Rihac'ek 1969] which generates high-resolution surface imagery from an aurborne or spaceborne platform, has generated interest in the scientific community for its use as an all-time all-weather remote sensor to study the earth s solid surface, oceans. and polar regions [Bradic 1967. Waite and MacDonald. 1970: Brown et al. 1973] The radar echo is a signature of the characteristics of the reflecting surface and immediate subsur face layer roughness slope distribution dielectr $c$ constant and layering. The penetration property of the radio waves allows a radar system to detect subsurface layers

A unique capability of the imaging radar is that it is an all weather all-time sensor because it provides its own illumination and usually operates in the microwave region of the elec tromagnetic spectrum to which clouds are transparent

In this paper we present a number of observations collected with the Jet Propulsion Laboratory (JPL) $L$ band (i.e., $25-\mathrm{cm}$ wavelength) imaging radar and VHF (2-m wavelength) sounder Specific data presented are sounding data taken over Greenland showing layering down to a depth of about $100 \mathrm{~m}$ and radar imagery of glaciers in southeast Alaska, nearcoast ice in northern Alaska, and sea ice cover in the Beaufort Sea.

The radar imagery shows a strong sımilarity to pho tographic imagery in many cases and differences in some cases. The conclusion of our observations is that the imaging radar sensor and photographic cameras are complementary and that the radar is a valuable sensor in its own right. especially because of its unıque capabilities: all-weather all-time capa bility and high resolution independent of the height of the platform (aircraft or spacecraft).

\section{Coherent Radar Imaging and Sounding Principle}

The resolution $u$ of a UV, optical, or IR sensor is propor tional to the operating wavelength $\lambda$, the platform height $H$, and the inverse of the aperture size $d$, i.e.,

$$
u \sim \lambda H / d
$$

The resolution achievable in these regions of the spectrum can be very small (in the range of a few meters) even from spacecraft altitudes. In the microwave region the resolution is drastically degraded because of the longer wavelength. The aperture size could be increased within reasonable limits, however, a high imaging resolution with microwaves can be achieved only from relatively low flying aircrafts. The coherent

\footnotetext{
Copyright () 975 by the American Geophy ical I nion.
}

radar synthetic aperture technıque circumvents this limitation by using the platform (aircraft or spacecraft) $\mathrm{m}$ )tion to generate an effective aperture far larger than the real aperture As a matter of fact, the theoretical resolution achievable is in dependent of the height For more detals see Harger [1970] and Rihaczek [1969].

Most imaging radars operate in the centimeter region and at grazing incidence angles. However, the imagery presented $n$ this paper was collected with a $25 \mathrm{~cm}$ radar operatıng at ne ir vertical incidence The brightness in the radar image is propor tional to the local radar backscatter cross section which $n$ turn is related to the surface roughness, slope distribution and dielectric constant [Barrick, 1968, Barrick and Peake 1968

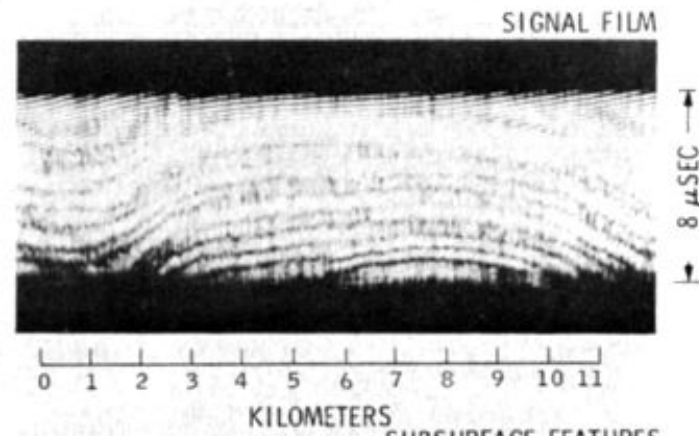

SUBSURFACE FEATURES

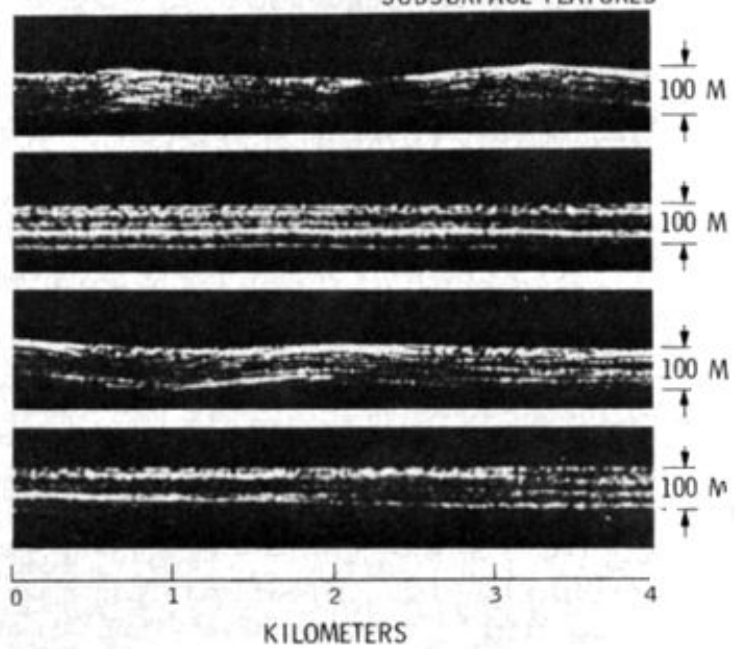

Fig. I Subsurface layers in the Greenland continental ce Ihe upper image corresponds to the radar data collected during the flight before processing. The lower images are four successive sections of the processed data of a continuous strip covering a $16-\mathrm{km}$ line. Up to 12 layers were detected in the upper $100 \mathrm{~m}$. In the upper section finger rafting' between the layers can be seen 
$6 \mathrm{~km}$

a

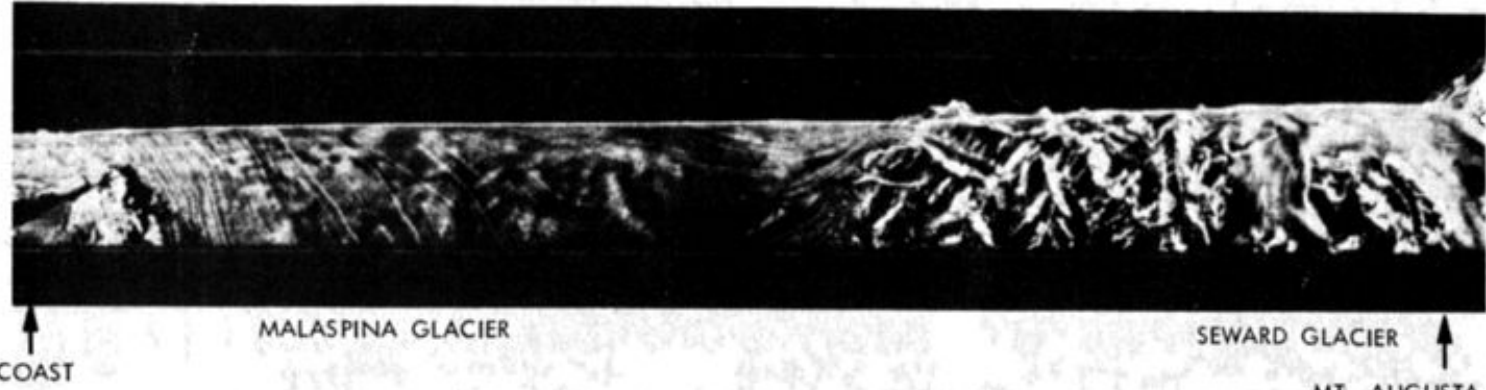

MT AUGUSTA

b

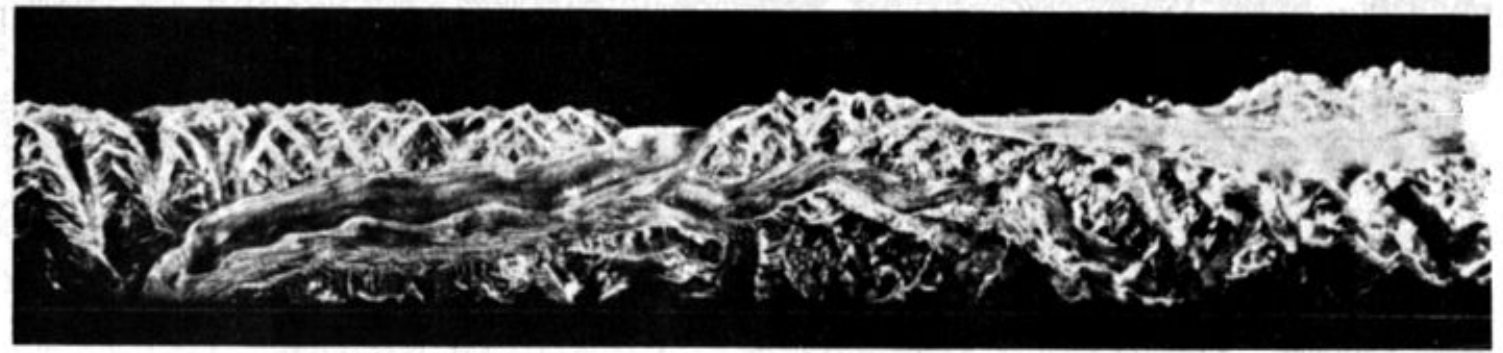

DUSTY GLACIER

LOWELL GLACIER

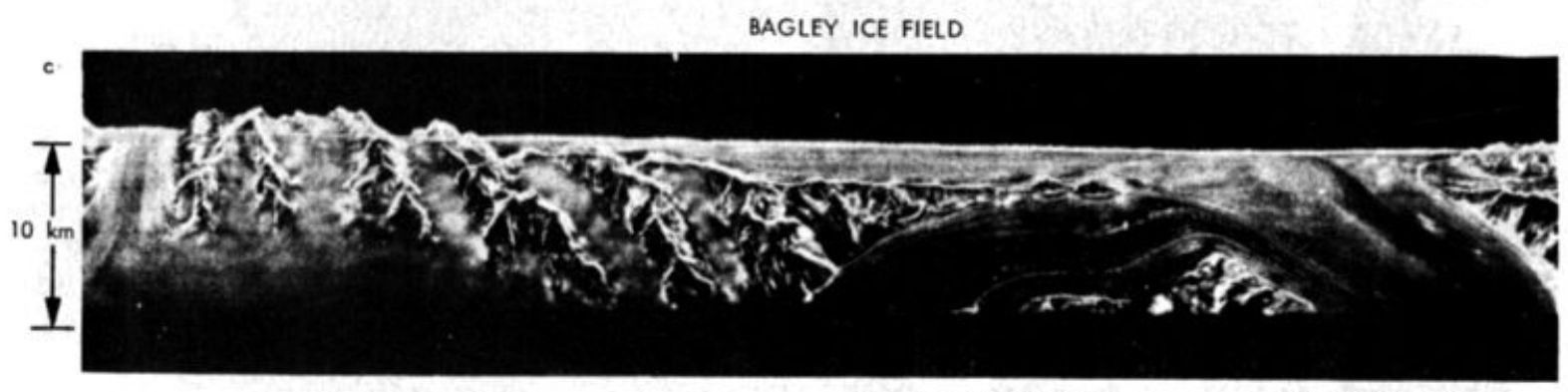

JEFFRIES GLACIERS

TANA GLACIER

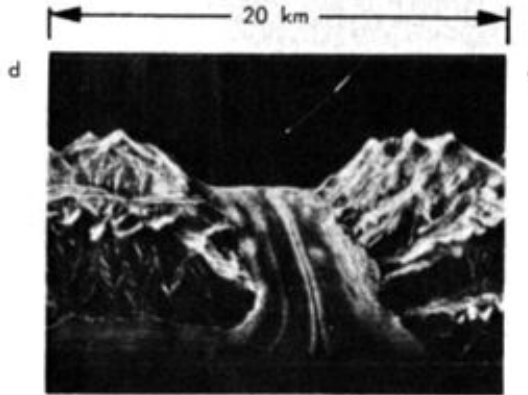

KASKAWULSH GLACIER

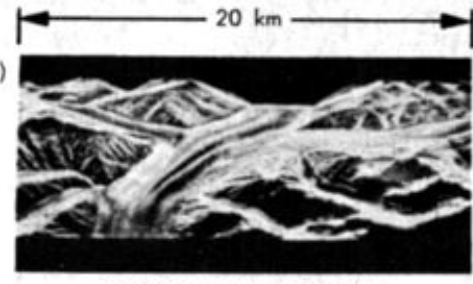

UPPER CHITINA GLACIER

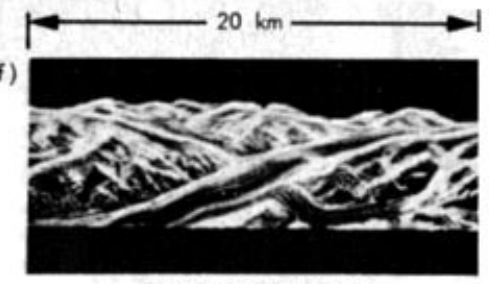

BAPNARD GLACIER

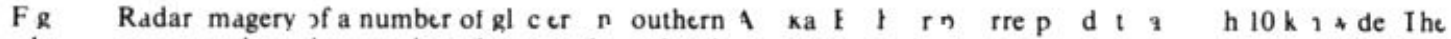
brgh ne rresp ndst the peculare $h \mathrm{r} m$ the nad $\mathrm{r}$ thu $\mathrm{tc}$ rre $\mathrm{p} d$ pr $\mathrm{te}$ ng the eoflght Ihe re of the nage to one $s$ de $f$ he ne o f ght ( ee $F$ gure $4 \mathrm{f} r$ ge $n$ tr

Kırshen 1971] For instance a ridge of a flow in an ce field will be imaged as a bright linear zone because the chaotic rough ice will backscatter strongly the electromagnet c wave Neu ice will be imaged with a tone different from that of old ice because of the change in surface roughness Similar v in glacier ımagery linear moraines and surface ripplings are clearly seen with sharply different tones

To achieve subsurface sounding longer wavelengths have to be used We conducted our observation with a $? \mathrm{~m}$ coherent radar (prototype of the Apollo 17 lunar sounder [Porcello et al 1974]) over Greenland to sound the continental ice sheet Any dielectric discontınuity would reflect an echo Deep sounding can be achieved in low loss contınental ce ficlds but not in sed ice

\section{OBSFRVATIONS}

Contınental ice sounding During airborne flight tests over Greenland in August 1972 the Apollo 17 lunar sounder rad ir detected manv dielectric discontinuities in the top laver of the ice cover (Figure 1) These discontinuities appeared laverlike 

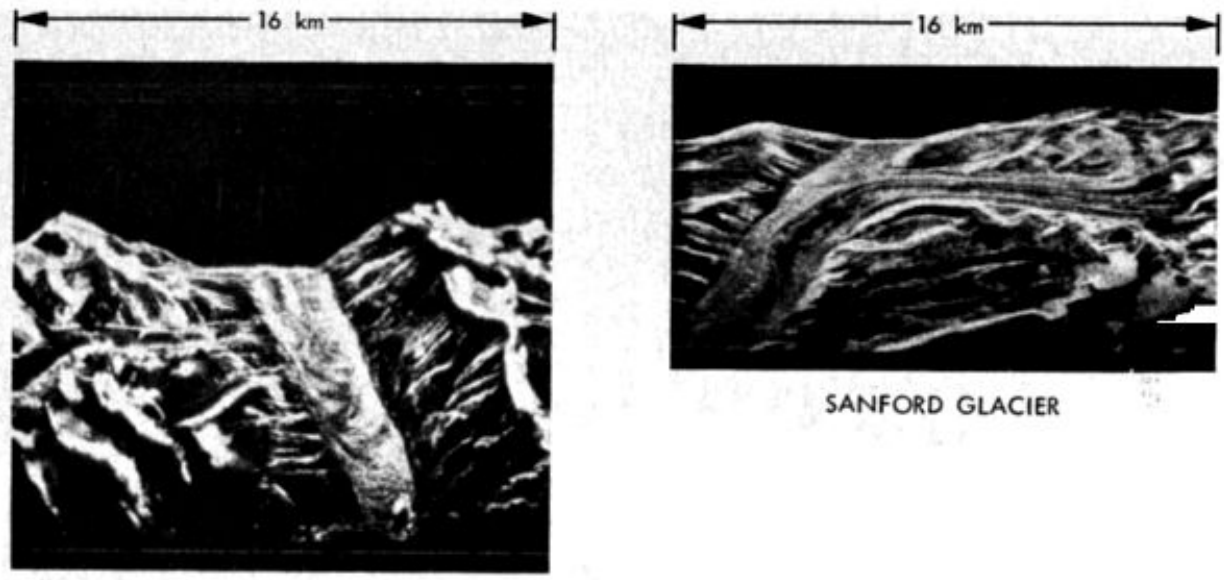

SANFORD GLACIER

STEELE GLACIER

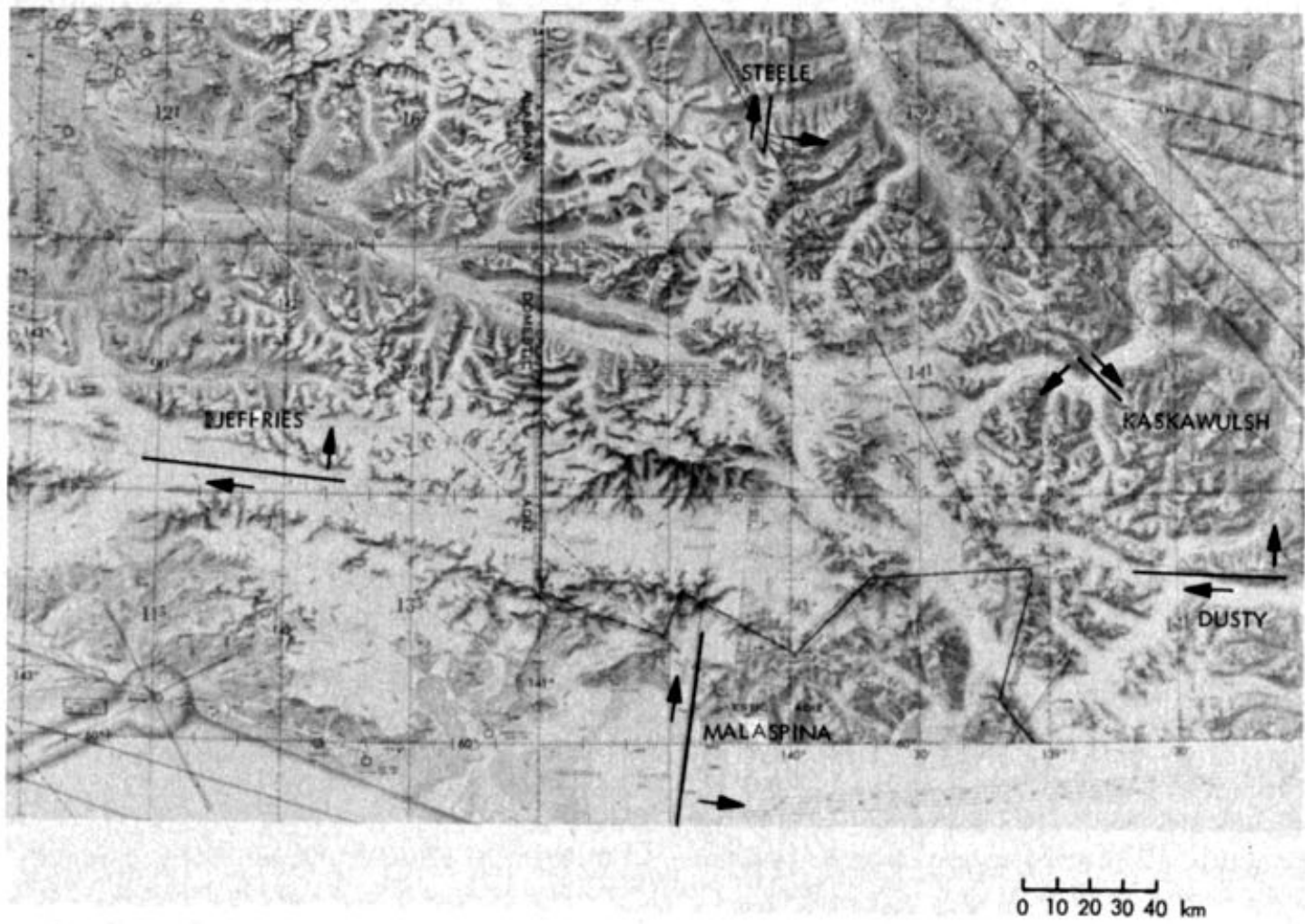

Fig. 3. Radar imagery of two glaciers and a topographic map showing the location of some of the glaciers that $u$ sre im aged. The lines correspond to the line of flight, and the two arrows shew the 9light direction and thi imaged sidr jaiwiys to the right of the aircraft).

and were detected over most of Greenland. The fight path $\mathbf{e}_{\text {. }}$ tended from the northwest coast $\left(60^{\circ}\right.$ longitude, $10^{\circ}>0$ latitude) to the southern coast $\left(40^{\circ} 12^{\prime}\right.$.ongitude. $60^{\circ} 30^{\prime}$ latitude) in a zigzag pattern down the central region of Greenland.

The in-depth sounding range was about $100 \mathrm{~m}$ below the surface (an estimated 200 years of accumulation;, and a dozen lavers ca be seen on the processed data (Figure 1). Some of these avers ref ected the electromagnetic wave even more than the suriace. The operating wavelength was $2 \mathrm{~m}(150 \mathrm{MHz})$ and the large penetration is due to the low loss in the continental $t$.

hr zuse $f$ the radai reflection is a discont!nuty in the

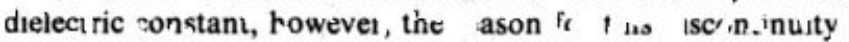

$5^{-}$- is wn at this time In interestilib hosel ralion is that

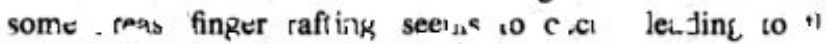
speculative suggestion of relative tre "sverse motion if different layers.

It should be emphasized that the VHF sounder used in our experiment is a suntilietir sper' ure radur that provicles 'erv high resolution botı. in _ept' (a few n.eters) and alon, the $i \mathrm{~s}$ of flight (abrut $15 \mathrm{~m}$ ). Thus it is somplementary to other ta lai sounders that use a 0 , utc force * chnique Gudmansen $1 \mathrm{~K}^{\prime}$ and ha ve lover resulutu n nes the surtace itor $100 \mathrm{~m}$, anta deeper penetration capa lits if $m$ or mure) (bna.ts an.

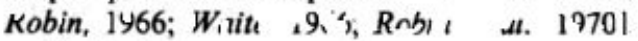
Glucier imax,
vul $x$.
115 s iो if 4 
SPA CRAF
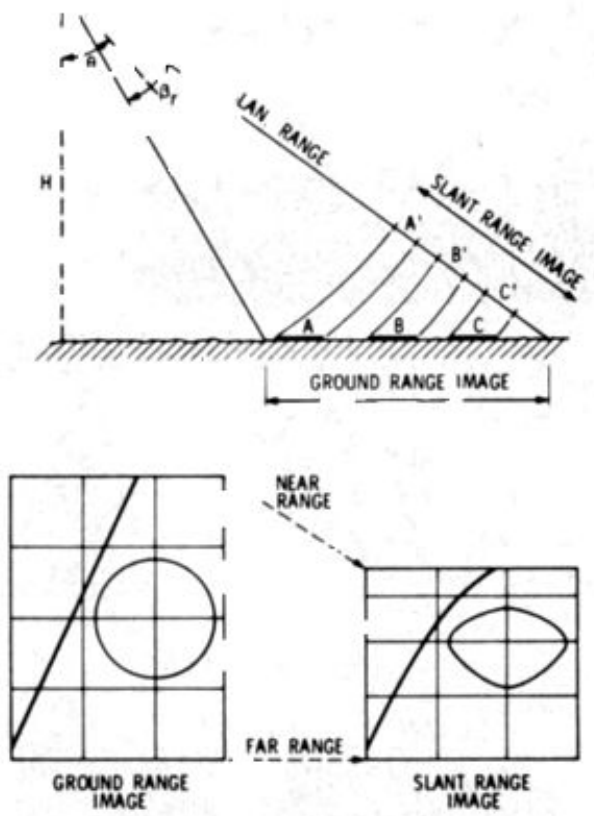

Fig. 4. Geometry of radar imagery. The radar measures the time delay (i.e. range) to a specific feature. Thus the ground image is projected on a time line called the slant range. Near-range features are compressed relative to far-range features. This distortion can be removed easily by digital processing. The platform could be an $r$ aft or a spacecraft.

the objectıve of imaging glaciers. The approximate area covered extended from $59^{\circ} 30^{\prime}$ to $62^{\circ}$ latitude, and $138^{\circ} 45^{\prime}$ longitude A sample of this imagery showing a variety of glaciers and the corresponding topographic map are shown in Figures 2 and 3

The geometry of radar imaging is different from that of photographic imagery. The radar imagery corresponds to an angle-time delay instead of the angle-angle geometry of stan dard photography (Figure 4). The bright line in the upper part of the radar image is the echo from the nadir Thus it corresponds to a profile of the surface along the flight track. The rest of the image corresponds to a swath of $10 \mathrm{~km}$ to the right of the flight track However it is projected on the radar line (Figure 4) and thus leads to some image geometric distortion particularly at near-vertical look angles

Figure $2 a$ is a radar image of the edstern part of the Malaspina piedmont glacier The line of flight $w$ as on the castern edge of the Seward glacier It is well known that the entering ice from the Seward glacier is forced into impressive horizontal fold patterns of fantastic scale and complexitv by the stagnant frontal area along the coast. These folds are clear ly seen on the radar imagery, and they are comparable to what is seen photographically [Gilluly et al., 1968]. These t slds start at the Seward glacier entrance and form large curvilinear lines that become parallel to the coast (at the left of Figure $2 a$ ). The width of the radar image swath in Figure $2 a$ is about $10 \mathrm{~km}$

Figure $2 b$ is a radar image of the Dusty glacier that clearly shows its boundaries and the medial moraine from the tributary at the left. The ridge of medial (below the junct.c $n$ ) and lateral moraine is also clearly seen in the image of the Tana-Jeffries glaciers (Figure 2c). The Kaskawulsh, upper Chitina, and Anderson glaciers imagery (Figures $2 d . \epsilon$ and $f$ ) shows most dramatically the moraine patterns in branching valley glacier systems.

The moraine ridges are clearly seen on radar imagery because of the change in roughness and the chaotic state of the ice at the boundary between the two flowing ice masses and because of the change of the dielectric constant due to the dirty ice and loose rocks. In the above imagery we can also see large patches of different tones (Figures $2 a, b$, and $c$ ) indicating variation in the surface roughness.

Figure 3 shows a topographic map of the area imaged dur ing the flights and the radar image (blown up) of the Steele and Sanford glaciers. The Steele glacier shows clearly the concave profiles of the ice flow that result from the differential motion of the ice across the glacier The Sanford glacier show s cle arly the moraine system and the transverse ripples all the way down the glacier flow line.

Coastal sea ice. A number of flights were conducted over the north Alaskan coast and the Beaufort Sea in conjunct on with the Aidjex mission Figure 5 shows radar imagery of coastal sea ice. The location of the coast is $69^{\circ} 36$ latitude and $140^{\circ} 15^{\prime}$ longitude and the flight line was to the north northwest The coastline can be seen clearly, and three successive boundary parallels to the coast were detected These boundaries were detected during many flights over a larøe sec tion of the coastline, and they most probably correspond to flaw zones separating different regions of fast ice and pack ice. The chaotic state of the ice in these narrow zones leads to increased surface roughness, resulting in a stronger radar return

Next to the shore a large number of medium and sm ill sized flows can be seen. No sizable fracturing or ridging is pres ent in the fast ice region Farther awdy from the coast manv young ce flows (dark to black tones are present in arge areas of ridged old ice (1 ght tones) Some new ,e flows have ridges

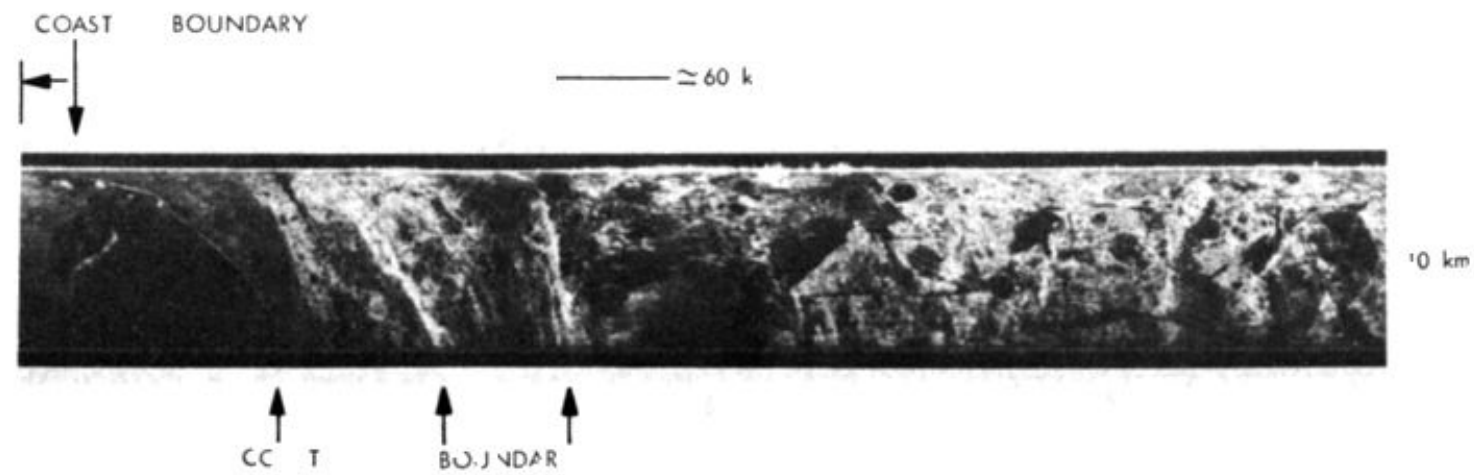

Fig 5 Radar image of or stal $c$ in northern Alaska The coast is $t$ the left Tr ree ice boundar es (flaw ) an be scen $t$ ) its right 1 large number of flows and ridges can be seen in the fas ce and pack ice areas. 

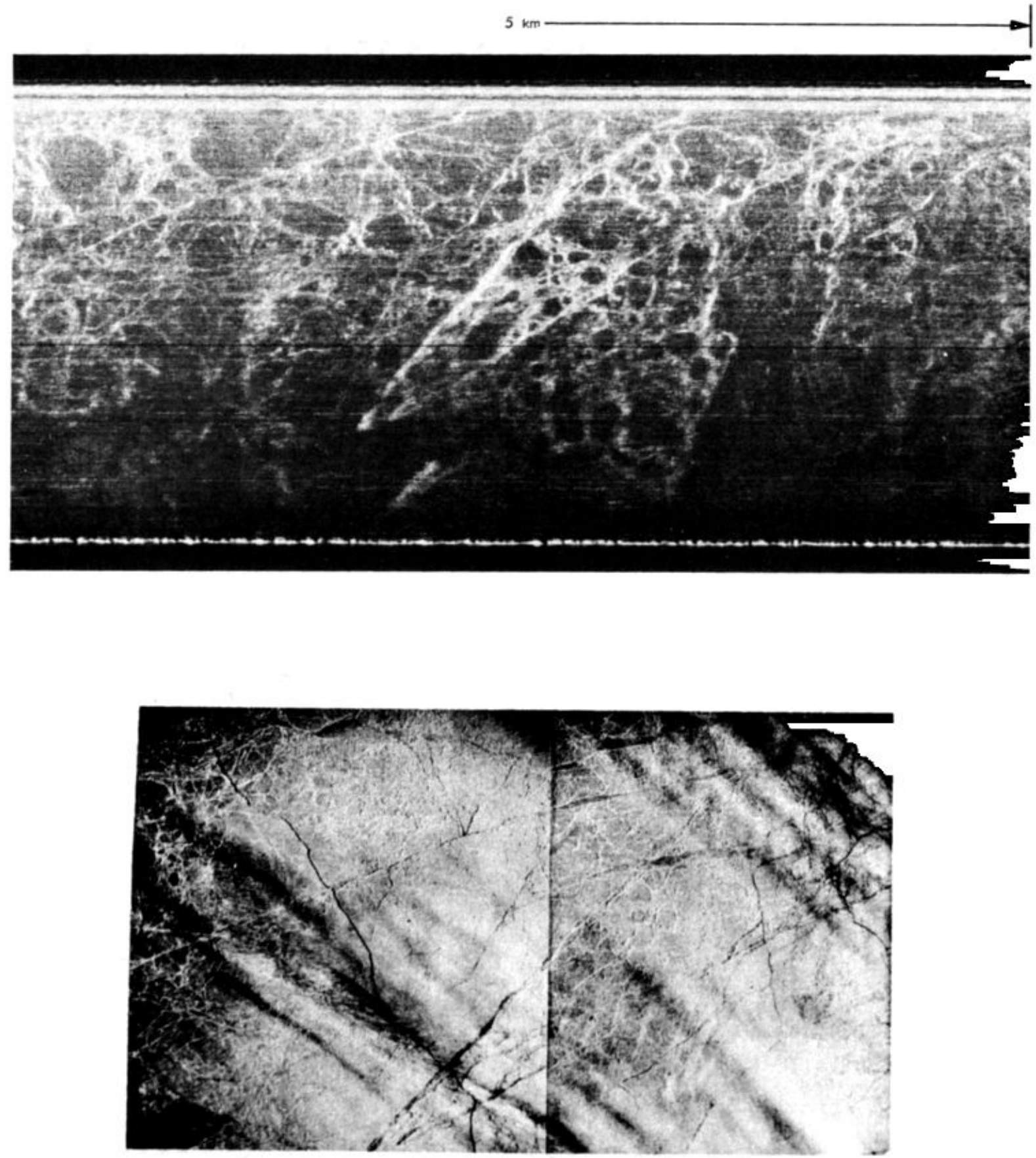

rig. 6 Sea ice $r$ dar and photo imager, in the Bea 'ort Sea

across them The large dark areas are most probably open water

The interpretation of radar ice imagery is still in its infancy. Somc $\mathrm{o}_{1} \mathrm{k}$ has been conducted recentl toward this objec ive (Raytheon Company) [Bradic 1967] and it seems that genı ral criteria for the identification of ice types can be generated However. more comparative work is still needed

Sea ice. In Figures 6 and 7 we show radar and photo imagerv of to $o$ areas in the Beaufort Sea $A$ large number of features can be seen on both images however the radar $\mathrm{m}$. agerv seems to be better in detecting and mapping pressure ridges and delineating ice flows. It appears that the radar visibility of a ridge is enhanced because the radio wave penerldies the driftung snow that ends to hide tre ridge in 1. $\quad\lrcorner F^{h} s \quad n d /$ also of poss b e that the radar waves are reflected from broken ice (scatterers) buried in the ridge system. In fact, the ridge width appears to be of the order of $100-200 \mathrm{~m}$ on radar imagery. This is an order of magnitude larger than surface ridges seen on the photograpi

On the other hand, photo imagery seems to be butter in the detection of leads However, other experimenters have mapped leads by using near-grazing [Johnson and Farmer 1971] Ku band imaging radars.

\section{Con tusiov}

In this paper we presented a small sample o rada imagery of glaciers, sea ice, and coastal ice fields and soundıng data of continental ice collected with airborne synthetic aperture radars. Jur understanding of the radar imaget of ice an it. compa titie 1 pre at on s 1 e it 7 a 

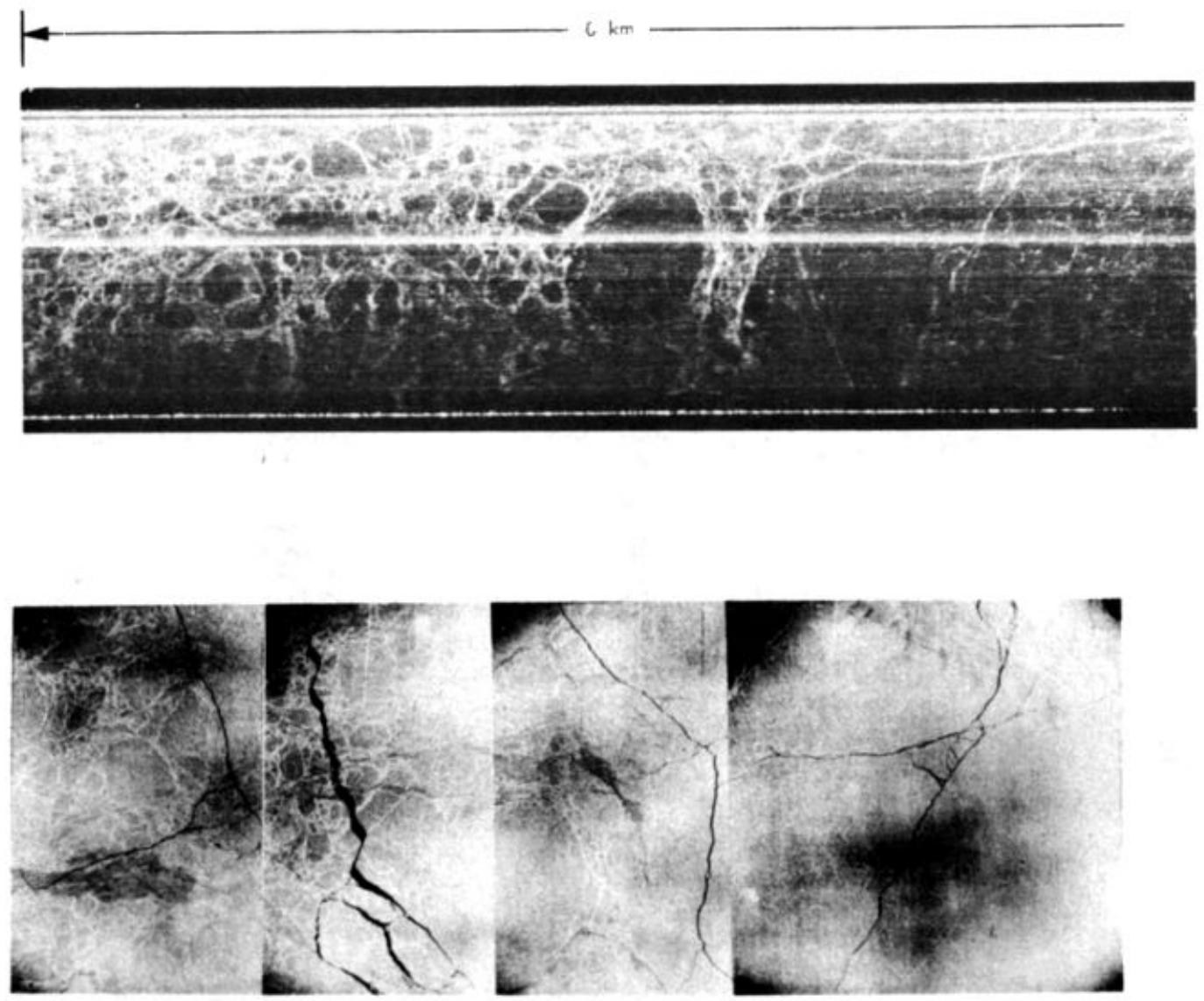

Fig. 7 Sea ice radar and photo imagery in the Beauf Sea

work is definitely needed. However, the imaging sounding radar seems to have significant potential as a remote sensor in the field of glaciology and polar ice study It is an all-weather all tıme system, and the presence of cloud cover, which is common in the polar areas, has no effect at all on the radar performance (some of the imagery presented in this paper was taken during complete cloud coverage). Another factor is that the altitude of the platform has little effect on the image resolutıon Thus similar imagery but with a much wider swath width can be obtained from orbiting spacecraft and will provide a far greater polar region coverage

In many cases the radar shows most of the features seen in a photograph Thus both systems can be considered as com plementary because the radar would extend the ımaging capability to the whole year regardless of cloud cover This is imp rrtant in the study of the dynamics of glaciers and ice covers On the other hand the radar sounder is basic ally the only svstem that can probe large areas in a reasonable amount of time and thus it can be used simultancously with local direct sounding

Finally it should be mentioned that the imaging and or sounding radar system has unique remote sensing capabilities for planetary exploration as well as for earth stud es Great in terest has recently been generated in the polar cap of M ars as a result of the Marıner Mars 1971 mission. The Martian polar caps are believed to consist of layers of water ice. dry ice, and dust An orbiting radar sounder would be a powerful tech. nıque for mappıng thıs layerıng
Acknowledgments We wish to thank $\mathrm{T}$ W Thomp on $\mathrm{r}$ a $\mathrm{n}$ helpful discussions and would also like to thank the members of the Science Radar Group, A. Laderman, E. Caro, and W Skotnick all from JPL, who contributed to collecting the data in this paper This paper presents the results of one phase of research carr ed cut at JPL Californı Institute of Technology, under contract NAS 7100 spon sored by the Nat nal Aer mnautics and Space Adm r strat $n$

\section{REFERENCES}

Barrick D E. Rough surface scattering based on specular $\mathrm{p} n \mathrm{nt}$ theory IEEE Irans Antennas Propagat API6 $44945 \quad 968$

Barrick D E and W H Peake, Review of scatter.ng from surfa es with fifferent roughness scales, Radio Sci 3 86.)-868 1968

Bradic, R A SI AR Imagery for sea ice studie Photogramm Eng $336366 \quad 196^{7}$

Br wn W E C Flachı nd T W Th mps n Ocean graph c ber t.ons $w$ th mag!ng radar paper presen ed Fal Meet $g$ L n Radi Sci Int Boulder Colo August 193

Evars. $S$ and $G$ de $Q$ Rob n. Glac er depth sound $\mathrm{rg}$ from he aur Vature $410 \quad 883 \quad 885 \quad 1966$

Gilluly J A C Water and $\mathrm{A} O \mathrm{~W}$ dford Prn ples of Geologv W H Free a n Sa Franc sco Ca f 1968

Harger R O Synthet 4perture Radar S sterns Acaden \& New York $19^{\prime \prime} 0$

J hhnson. J D and I D F armer I se f side look ng arb srne

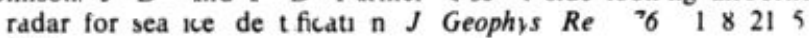
19 ㄱ1

K rshen $K \quad$ C srrela $r$ of radar ba ksca terng cr ect $n$ s w $h$ sean wave height and wind velocity $J$ Ge,phys Res 6 6528-6539 191

Porcello. I R Jordan J S Zelenka G F Adams R J Fh llips W F. Brown $\mathrm{Jr} \mathrm{S} \mathrm{H}$ Ward and P I Jackson The Ap rlo unar $\begin{array}{lllll}\text { zunder } s & \text { sten Proc IEFF } 6 & 69-83 & 19^{7} 4\end{array}$ 
Rihaczek, A. W., Principles of High Resolution Radar, McGraw-Hill, New York, 1969.

Robin, G. de Q., S. Evans, D. J. Drewry, C. H. Harrison, and D. L. Petric, Radio-echo sounding of the Antarctic ice sheet, Antarctic $J$. U.S., 5, 229-232, 1970.

Waite, A. H., Jr., International experiment in glacier sounding, 1963 and 1964, Can. J. Earth Sci., 3, 887-892, 1966.
Waite, W. P., and H. P. MacDonald, Snowfield mapping with K-band radar, Remote Sensing, 1, 143-150, 1970.

(Received July 29, 1974; revised November 20, 1974; accepted December 10, 1974.) 